\title{
Diferencias entre el modelo de justicia transicional aplicable a las FARC-EP y el aplicado a las Autodefensas Unidas de Colombia*
}

\author{
Differences between the model of transitional justice applicable to the FARC- \\ $\mathrm{EP}$ and the one applied to the AUC \\ Janiel Melamed Visbal $^{* *}$
}

\begin{abstract}
Resumen
El conflicto armado colombiano es una de las guerras de mayor duración en el mundo contemporáneo, y paradójicamente se presenta al interior de un país con una numerosa y larga experiencia en procesos de paz y mecanismos de concertación dirigidos a obtener una salida del mismo. Colombia ha sido pionera en Latinoamérica en la realización de procesos de negociación con grupos guerrilleros y en la búsqueda de acuerdos de paz desde la década de los noventa; sin embargo, aún se mantiene como el único estado de la región que evidencia una confrontación armada a gran escala como consecuencia de manifestaciones de violencia política.

La justicia transicional se ha convertido por ende, en un tema absolutamente central frente al propósito de encontrar los mecanismos judiciales y extrajudiciales para lograr una salida negociada al conflicto. La primera experiencia transicional en Colombia fue creada mediante la Ley 975 de 2005, la cual implemento un modelo de justicia transicional con las Autodefensas Unidas de Colombia (AUC). Este modelo de justicia transicional ha sido muy controversial y ha generado desconfianza y rechazo en diversos sectores sociales en el país frente a la implementación de un nuevo modelo de justicia transicional acordado con las FARC-EP. En este sentido, vale la pena analizar ¿cuáles son las principales diferencias entre los modelos de justicia transicional diseñados para las AUC y las FARC-EP?
\end{abstract}

Palabras clave: Colombia; Justicia Transicional; Conflicto armado; AUC; FARC-EP.

\footnotetext{
* Este artículo de investigación hace parte del trabajo de investigación doctoral en Seguridad Internacional realizado por el autor

** Colombiano, Magister en Gobierno, Seguridad Nacional y Contraterrorismo de la Lauder School of Government, Diplomacy and Strategy (Herzliya-Israel) y Doctorando en Seguridad Internacional de la Universidad Nacional de Educación a Distancia (UNED), a través del Instituto Universitario General Gutiérrez Mellado (IUGM). Actualmente es docente investigador del Departamento de Ciencia Política y Relaciones Internacionales de la Universidad del Norte en Barranquilla-Colombia. jmelamed@uninorte.edu.co
}

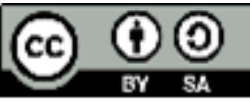




\begin{abstract}
The ongoing colombian armed conflict is one of the longest wars in the contemporary world, and paradoxically it is taking place in a country with a large experience in the development and implementation of peace agreements. Colombia has been a pioneer in Latin America in conducting negotiation processes with guerrilla groups and in seeking peace agreements since the nineties; however, it still remains the only state in the region which shows a large-scale armed confrontation as a result of manifestations of political violence.

Transitional justice has become therefore an absolutely central issue facing the purpose of finding judicial and extrajudicial means to achieve a negotiated solution to the conflict. The first transitional experience in Colombia was developed through Law 975 of 2005, which implemented a transitional model with the Autodefensas Unidas de Colombia (AUC). This transitional model has been very controversial, creating a sense of distrust and rejection in several social groups in the country about the implementation of a new transitional model agreed with the Fuerzas Armadas Revolucionarias de Colombia (FARC$\mathrm{EP})$. In this sense it is necessary to analyze which are the main differences between the transitional models designed for the AUC and the FARC-EP?
\end{abstract}

Key words: Colombia; Transitional justice; Armed Conflict; AUC; FARC-EP.

Recibido: 5 octubre 2016

Aceptado: 6 enero 2017

\title{
1. INTRODUCCIÓN.
}

La justicia transicional $^{1}$ se puede entender como una variedad de figuras y disposiciones transitorias del derecho que, en el caso colombiano procura mediante la concertación de un modelo de justicia, facilitar un tránsito del conflicto al posconflicto. Es por esto, que al interior del proceso de negociación adelantado en La Habana entre el Gobierno nacional y las FARC-EP, quizás el punto que mayor expectativa generaba tanto a las partes inmersas en la negociación, como al país y a la comunidad internacional en general, era el punto en la agenda de diálogos referente a la adopción de un instrumento de justicia que facilitará la

\footnotetext{
${ }^{1}$ Para una mayor delimitación conceptual véase: Elster, J. (2004). Closing the Books: Transitional Justice in Historical Perspective ; Hayner, P. (2002). Unspeakable truths: Transitional justice and the challenge of truth commissions. Nueva York: Routledge ; Mani, R. (2002). Beyond retribution: Seeking justice in the shadows of war. Malden: Blackwaell; Minow, M. (1998). Between vengeance and forgiveness facing history after genocide and mass violence. Boston: Beacon Press; Van Zyl, P. (2008). Promoviendo la Justicia transicional en sociedades post-conflicto. En Verdad, memoria y reconstrucción Estudios de caso y análisis comparado. Bogotá: International Center for Transitional Justice.
}

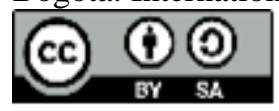


concertación de una salida pacífica al conflicto sin que ello derivara en una impunidad generalizada y además permitiera el tránsito a la legalidad de las FARC-EP a la vida política nacional $^{2}$.

En el mes de septiembre del año 2015, las partes dieron a conocer mediante el comunicado conjunto \#60, el acuerdo al que habían llegado para la creación de una justicia especial para la paz, en la cual se habría de otorgar la amnistía más amplia posible por delitos políticos y conexos. Este y otros comunicados posteriores, han generado un profundo rechazo desde diversos sectores políticos y sociales que afirman que la concesión de amnistías por delitos políticos, la imposición de medidas punitivas especiales, entre las que se incluyen penas alternativas y sanciones reducidas, así como la participación desde la legalidad de las FARC-EP en la política nacional, hacen de este proceso de negociación una farsa de impunidad peor al modelo transicional adoptado con las Autodefensas Unidas de Colombia (AUC).

Estas circunstancias, hacen necesario desarrollar un análisis crítico del acuerdo adoptado entre el gobierno y las FARC-EP frente al tema de justicia y víctimas, sus alcances, efectos, su relación con la posibilidad de participación política de las FARC-EP, las reformas que subyacen en cada caso y las principales diferencias existentes entre este instrumentos de justicia transicional y el adoptado anteriormente con las AUC mediante la Ley 975 de 2005.

\section{Contenido del acuerdo sobre justicia transicional y víctimas acordado con las FARC-EP}

El acuerdo adoptado entre las partes contiene el objetivo de crear un Sistema Integral de Verdad, Justicia, Reparación y No Repetición (SIVJRNR), para lo cual han acordado crear una serie de instituciones y mecanismos propios de la justicia transicional, que garanticen los derechos a las víctimas y faciliten el fin del conflicto. Dada la extensión del acuerdo, para mayor ilustración se procederá a realizar una breve explicación de cada uno de los cinco componentes que han sido diseñados al interior de este sistema integral de justicia.

En primer lugar el SIVJRNR estará integrado por una Comisión para el Esclarecimiento de la Verdad, la Convivencia y la no Repetición (CEVCNR), cuyas principales características se fundamentan en el hecho de representar un órgano de carácter temporal y de naturaleza extrajudicial, encargado de indagar verazmente la realidad de lo ocurrido durante el conflicto, con el propósito de proporcionar con ello un esclarecimiento integral a la sociedad colombiana en torno a las difíciles circunstancias que históricamente han rodeado

\footnotetext{
${ }^{2}$ El Acuerdo final para la terminación del conflicto entre el Gobierno y las FARC-EP establece que la imposición de cualquier sanción al interior del Sistema Integral de Verdad, Justicia, Reparación y Garantías de no Repetición no inhabilitara para la participación política ni limitara el ejercicio de ningún derecho, activo o pasivo de participación política, por lo cual las partes acordaran reformas constitucionales pertinentes (p. 150, numeral 36).
} 
al conflicto y aportar en la construcción de unas condiciones de convivencia social enmarcadas en la tolerancia, la aceptación y el respeto, en aras de evitar una eventual repetición de hechos victimizantes.

El segundo componente de este sistema integral de justicia está enmarcado en la creación de una Unidad Especial para la Búsqueda de Personas (UEBP), que al igual que la CEVCNR, será una unidad de carácter temporal, establecida para coordinar la implementación de acciones humanitarias de localización e identificación de aquellos ciudadanos, vivos o muertos, que hayan sido considerados como desaparecidos como consecuencia directa o indirecta del conflicto. El tercer componente es la Jurisdicción Especial para la Paz (JEP) ${ }^{3}$, la cual estará conformada por una serie de salas de justicia, de tal manera que pueda cumplir con el objetivo de conceder amnistías por delitos políticos y conexos, administrar justicia a través de la investigación, juzgamiento y sanción de las graves violaciones a los Derechos Humanos y al Derecho Internacional Humanitario ocurridos con ocasión al conflicto, e imponer medidas punitivas que prevén sanciones especiales que incluyen penas reducidas y sanciones alternativas.

En cuarto lugar se encuentran una serie de medidas de reparación integral para la construcción de una paz estable y duradera, entre las cuales se incluyen el derecho a la restitución, la reparación colectiva en aquellos territorios, poblaciones y colectivos de individuos que hayan sido afectados en gran medida por el conflicto, la indemnización monetaria, la rehabilitación psicológica y social, la satisfacción de sus derechos y las garantías necesarias de no repetición. Precisamente estas garantías en torno a la creación de unas condiciones transformadores que impidan la ocurrencia futura de nuevos hechos victimizantes, se constituye como el último componente de esta sistema integral de justicia, como el resultado natural de la implementación coordinada de todas las medidas y mecanismos establecidos en el acuerdo adoptado finalmente entre el Gobierno nacional y las FARC-EP. Luego de haber determinado las características generales de los componentes del acuerdo del sistema integral de justicia, se procederá a realizar una caracterización de los principales ejes temáticos que diferencian este modelo de transición del implementado con las AUC.

3. Diferencias entre la justicia transicional aplicable a las FARC-EP y la justicia transicional aplicada a las AUC

Al desarrollar un estudio de las disposiciones inmersas en el acuerdo de justicia y víctimas, se hace evidente que entre esta experiencia de justicia transicional y el anterior antecedente evidenciado con las AUC, existen profundas diferencias. En la siguiente Tabla, se ha

\footnotetext{
${ }^{3}$ La Jurisdicción Especial para la Paz es un modelo de justicia integrado al acuerdo general para la terminación del Conflicto y la construcción de una Paz estable y duradera, como base de los diálogos desarrollados entre el Gobierno nacional y las FARC-EP desde el 2012.
}

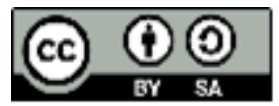


determinado la existencia de al menos 11 importantes circunstancias que condicionan la existencia de dos modelos de justicia transicional absolutamente diferentes entre sí.

Tabla 1. Diferencias acuerdos de Justicia Transicional AUC y FARC-EP.

\begin{tabular}{|c|c|c|c|c|c|c|c|c|c|c|c|}
\hline Diferencias & $\begin{array}{l}\text { ¿Quiénes } \\
\text { están } \\
\text { cobijados? }\end{array}$ & $\begin{array}{l}\text { Sanciones } \\
\text { Estipuladas }\end{array}$ & $\begin{array}{l}\text { Participación } \\
\text { en Política }\end{array}$ & $\begin{array}{l}\text { Esclarecimiento } \\
\text { de Hechos }\end{array}$ & Indultos & $\begin{array}{c}\text { Autoridades } \\
\text { Judiciales }\end{array}$ & $\begin{array}{l}\text { Participación } \\
\text { de Victimas }\end{array}$ & $\begin{array}{l}\text { Selectividad de } \\
\text { Casos }\end{array}$ & $\begin{array}{c}\text { Entrega de } \\
\text { Armas }\end{array}$ & Extradición & Refrendación \\
\hline $\begin{array}{c}\text { Acuerdo } \\
\text { Justicia y } \\
\text { Paz (AU) }\end{array}$ & $\begin{array}{c}\text { Paramilitares } \\
\text { miembros de } \\
\text { las AUC }\end{array}$ & $\begin{array}{c}\text { Pena } \\
\text { alternativa de } \\
\text { privación de la } \\
\text { libertad entre } 5 \\
\text { y } 8 \text { años de } \\
\text { cárcel, sin } \\
\text { importar el } \\
\text { delito que } \\
\text { hubiesen } \\
\text { cometido. Por } \\
\text { incumplimiento } \\
\text { aplicarian } \\
\text { sanciones } \\
\text { propias del } \\
\text { sistema penal } \\
\text { ordinario }\end{array}$ & $\begin{array}{l}\text { Este punto } \\
\text { no fue } \\
\text { negociado } \\
\text { por tratarse } \\
\text { de una } \\
\text { organización } \\
\text { que adolecía } \\
\text { de status } \\
\text { político }\end{array}$ & $\begin{array}{c}\text { La } \\
\text { configuración } \\
\text { de una } \\
\text { narrativa de } \\
\text { memoria } \\
\text { histórica fue } \\
\text { supeditada a la } \\
\text { confesión } \\
\text { realizada por } \\
\text { los miembros } \\
\text { de las AUC. }\end{array}$ & $\begin{array}{c}\text { No se } \\
\text { estipularon } \\
\text { amnistías o } \\
\text { indultos, pero } \\
\text { si una } \\
\text { suspensión } \\
\text { de la pena } \\
\text { para los } \\
\text { paramilitares } \\
\text { que } \\
\text { contribuyesen } \\
\text { a la verdad. }\end{array}$ & $\begin{array}{c}\text { La } \\
\text { responsabilidad } \\
\text { de impartir } \\
\text { justicia fue } \\
\text { enteramente } \\
\text { cobijada por } \\
\text { autoridades } \\
\text { nacionales. }\end{array}$ & $\begin{array}{c}\text { Ausentes en } \\
\text { el diseño del } \\
\text { mecanismo de } \\
\text { justicia que } \\
\text { fue } \\
\text { implementado. }\end{array}$ & $\begin{array}{c}\text { Inicialmente se } \\
\text { juzgaron todos los } \\
\text { casos conocidos } \\
\text { por este modelo } \\
\text { de justicia. Luego } \\
\text { ante la notoria } \\
\text { limitación de las } \\
\text { capacidades } \\
\text { judiciales } \\
\text { nacionales se } \\
\text { aplicaron criterios } \\
\text { de selección y } \\
\text { priorización. }\end{array}$ & $\begin{array}{c}\text { Fue paulatina, } \\
\text { con } 4 \text { años de } \\
\text { duración } \\
\text { aproximada, en } \\
\text { la medida en } \\
\text { que se iban } \\
\text { desmovilizando } \\
\text { los distintos } \\
\text { bloques } \\
\text { paramilitares. }\end{array}$ & $\begin{array}{c}\text { Condicionada } \\
\text { al } \\
\text { cumplimiento } \\
\text { de } \\
\text { obligaciones } \\
\text { en aportes a } \\
\text { verdad, } \\
\text { justicia, } \\
\text { reparación y } \\
\text { garantías de } \\
\text { no repetición. }\end{array}$ & $\begin{array}{c}\text { No se realizó } \\
\text { ningún } \\
\text { mecanismo } \\
\text { de } \\
\text { refrendación. }\end{array}$ \\
\hline $\begin{array}{c}\text { Jurisdicción } \\
\text { Especial } \\
\text { para la Paz } \\
\text { (FARC-EP) }\end{array}$ & $\begin{array}{l}\text { Todos los } \\
\text { actores del } \\
\text { conflicto: } \\
\text { Civiles, } \\
\text { miembros de } \\
\text { la fuerza } \\
\text { pública, } \\
\text { guerrilleros } \\
\text { de las } \\
\text { FARC-EP. }\end{array}$ & $\begin{array}{l}\text { Tres tipos de } \\
\text { sanciones: } \\
\text { 1) } 5 \text { a } 8 \text { años } \\
\text { de restricción } \\
\text { efectiva de la } \\
\text { libertad. } \\
\text { 2) } 5 \text { a } 8 \text { años } \\
\text { de cárcel en } \\
\text { condiciones } \\
\text { ordinarias. } \\
\text { 3) Entre } 15 \text { y } \\
20 \text { años de } \\
\text { cárcel en } \\
\text { condiciones } \\
\text { ordinarias. }\end{array}$ & $\begin{array}{c}\text { La } \\
\text { imposición } \\
\text { de } \\
\text { sanciones } \\
\text { en el } \\
\text { SIVJRNR no } \\
\text { inhabilita la } \\
\text { participación } \\
\text { política. }\end{array}$ & $\begin{array}{l}\text { Se determinó la } \\
\text { creación de } \\
\text { una Comisión } \\
\text { de la Verdad, la } \\
\text { convivencia y la } \\
\text { no repetición, } \\
\text { para identificar } \\
\text { y establecer las } \\
\text { raíces causales } \\
\text { del conflicto y } \\
\text { sus dinámicas. }\end{array}$ & $\begin{array}{c}\text { Serán } \\
\text { amnistiados } \\
\text { por delitos } \\
\text { políticos y } \\
\text { conexos. } \\
\text { Esta figura no } \\
\text { se aplicará } \\
\text { para delitos } \\
\text { de Lesa } \\
\text { Humanidad u } \\
\text { otro } \\
\text { estipulado en } \\
\text { el Estatuto de } \\
\text { Roma. }\end{array}$ & $\begin{array}{l}\text { La JEP } \\
\text { contempla } \\
\text { Juristas } \\
\text { extranjeros, } \\
\text { quienes } \\
\text { participaran en } \\
\text { el proceso a } \\
\text { petición del } \\
\text { acusado a } \\
\text { modo de } \\
\text { amicus curiae } \\
\text { (amigo de la } \\
\text { corte). }\end{array}$ & $\begin{array}{l}\text { Participación } \\
\text { de las } \\
\text { víctimas en el } \\
\text { proceso de } \\
\text { negociación } \\
\text { entre las } \\
\text { partes. } \\
\text { Presentación } \\
\text { de propuestas } \\
\text { a la mesa de } \\
\text { negociación } \\
\text { en La Habana } \\
\text { y foros } \\
\text { nacionales y } 4 \\
\text { foros } \\
\text { regionales. }\end{array}$ & $\begin{array}{c}\text { Se podrán aplicar } \\
\text { desde el inicio de } \\
\text { su } \\
\text { implementación, } \\
\text { criterios de } \\
\text { selección y } \\
\text { priorización y el } \\
\text { principio de } \\
\text { Macrocriminalidad } \\
\text { para los casos } \\
\text { más } \\
\text { representativos. }\end{array}$ & $\begin{array}{l}\text { No se estipula } \\
\text { entrega de } \\
\text { armas, sino } \\
\text { dejación de } \\
\text { armas. } \\
\text { Programada } \\
\text { para que } \\
\text { ocurra en un } \\
\text { periodo de } \\
\text { tiempo de } 180 \\
\text { días después } \\
\text { de firmado el } \\
\text { acuerdo final } \\
\text { entre las } \\
\text { partes. }\end{array}$ & $\begin{array}{c}\text { No } \\
\text { extradición } \\
\text { para } \\
\text { integrantes } \\
\text { de las FARC- } \\
\text { EP o } \\
\text { personas } \\
\text { acusadas de } \\
\text { pertenecer a } \\
\text { esta } \\
\text { organización, } \\
\text { por hechos } \\
\text { ocurridos con } \\
\text { anterioridad a } \\
\text { la adopción } \\
\text { del acuerdo. }\end{array}$ & $\begin{array}{l}\text { Se estipulo } \\
\text { la } \\
\text { refrendación } \\
\text { de los } \\
\text { acuerdos por } \\
\text { parte de la } \\
\text { ciudadanía. } \\
\text { El Plebiscito } \\
\text { realizado en } \\
\text { el mes de } \\
\text { octubre de } \\
2016 \text { para } \\
\text { obtener la } \\
\text { refrendación } \\
\text { del acuerdo. }\end{array}$ \\
\hline
\end{tabular}

Fuente: Elaboración propia con base en información contenida en El Colombiano (2015), El Universal (2015), Pulzo (2015).

El primer elemento diferenciador, son los individuos cobijados en cada uno de ellos. En el proceso implementado a través de la Ley 975 de 2005, pese a haber sido presentado como un esfuerzo de transición que facilitaría la búsqueda de la paz y la reincorporación a la vida civil de los miembros de las diversas organizaciones armadas al margen de la ley, en realidad cobijaba exclusivamente a paramilitares miembros de las AUC. Por lo tanto, en este caso nos encontramos ante un modelo de justicia transicional parcial, pues en primer lugar, a él no se acogieron todos los actores armados ilegales inmersos en el conflicto armado interno y en segundo lugar, no cobijaba el tratamiento a las igualmente graves violaciones a los derechos humanos cometidos por diversos agentes estatales en razón del conflicto.

En el modelo de justicia acordado entre el Gobierno nacional y las FARC-EP, se encuentran cobijadas todas las partes que directa o indirectamente hubiesen participado del conflicto armado colombiano por igual, por lo cual este modelo de justicia es igualmente aplicable incluso a individuos que se encuentren investigados o juzgados por delitos de rebelión u otros relacionados al conflicto, aún cuando éstos no pertenezcan a las distintas organizaciones subversivas que se encuentran en rebelión armada contra el Gobierno. La amplia cobertura de este acuerdo de justicia también se refleja en la inclusión, tanto de las conductas de individuos pertenecientes a la sociedad civil que hayan prestado financiación

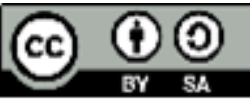


o colaboración con grupos paramilitares que no sean resultado de presiones o mecanismos de coerción por parte de estas organizaciones y que no hayan sido condenados por la justicia ordinaria por estas mismas acciones, así como de los delitos relacionados con el conflicto armado realizados por agentes del Estado.

Un segundo elemento de diferenciación puede ser establecido en las sanciones que ambos modelos de justicia presentan con el propósito de facilitar el tránsito hacia el fin del conflicto. En este sentido, el modelo planteado por la Ley 975 de 2005 estipula una alternatividad penal, consistente en la privación de la libertad en condiciones ordinarias al interior de centros carcelarios, por un periodo mínimo de 5 años y un máximo de 8 años. Esta circunstancia es aplicable para aquellos paramilitares miembros de las AUC que cumplan con las condiciones estipuladas por dicho instrumento normativo, sin distinción del delito cometido en razón del conflicto armado.

En el acuerdo de justicia entre el Gobierno y las FARC-EP, en cambio, no existe una pena única, pues tal como se ha señalado se presentan tres posibles penas dependiendo del grado de aceptación de la responsabilidad en la comisión de delitos al interior del conflicto. En este sentido, la pena más flexible en este acuerdo estipula una sanción acorde a un reconocimiento inicial de las responsabilidades criminales frente a las conductas más graves y representativas que hayan sido cometidas con ocasión del conflicto armado; caso para el cual se han establecido penas alternativas a la privación de la libertad, desarrolladas en unas condiciones especiales que distan de las tradicionalmente establecidas al interior de un centro de reclusión ordinario, tal como se describe en la siguiente tabla. En este caso, las penas para quienes reconozcan su responsabilidad y participación determinante en hechos victimizantes, tendrán una duración que oscila entre los 5 y los 8 años de restricción efectiva de la libertad ${ }^{4}$ y entre 2 y 5 años para quienes no hayan tenido una participación determinante en las conductas, aun habiendo interviniendo en ellas.

Tabla 2. Lista de sanciones aplicables a quienes reconozcan verdad exhaustiva, detallada y plena en la Sala de reconocimiento de verdad y responsabilidades.

\begin{tabular}{|l|l|l|}
\hline ZONAS RURALES & ZONAS URBANAS & LIMPIEZA Y ERRADICACION DE EXPLOSIVOS MUSE5, MIAP6 \\
\hline $\begin{array}{l}\text { Participación/Ejecución en programas de reparación } \\
\text { efectiva para los campesinos desplazados. }\end{array}$ & $\begin{array}{l}\text { Participación/Ejecución en programas de } \\
\text { construcción y reparación de infraestructuras } \\
\text { en zonas urbanas: escuelas, vías públicas, } \\
\text { centros de salud, viviendas, centros } \\
\text { comunitarios, infraestructura de municipios, } \\
\text { etc. }\end{array}$ & $\begin{array}{l}\text { Participación/Ejecución en programas de limpieza y erradicación de restos explosivos de } \\
\text { guerra y municiones sin explotar. }\end{array}$ \\
\hline $\begin{array}{l}\text { Participación/Ejecución en programas de protección } \\
\text { al medio ambiental en zonas de reserva. }\end{array}$ & $\begin{array}{l}\text { Participación/Ejecución en programas de } \\
\text { desarrollo urbano. }\end{array}$ & $\begin{array}{l}\text { Participación/Ejecución en programas de limpieza y erradicación de minas antipersonales } \\
\text { y aparatos explosivos improvisados. }\end{array}$ \\
\hline Participación/Ejecución en programas de & Participación/Ejecución en programas de & \\
\hline
\end{tabular}

${ }^{4}$ La restricción efectiva implica la existencia de diversos mecanismos de monitoreo y supervisión para asegurar el efectivo cumplimiento de las restricciones ordenadas por la Jurisdicción Especial para la Paz.

${ }^{5}$ Munición sin explotar.

${ }^{6}$ Minas Antipersonales.

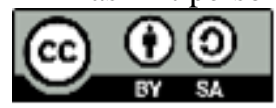




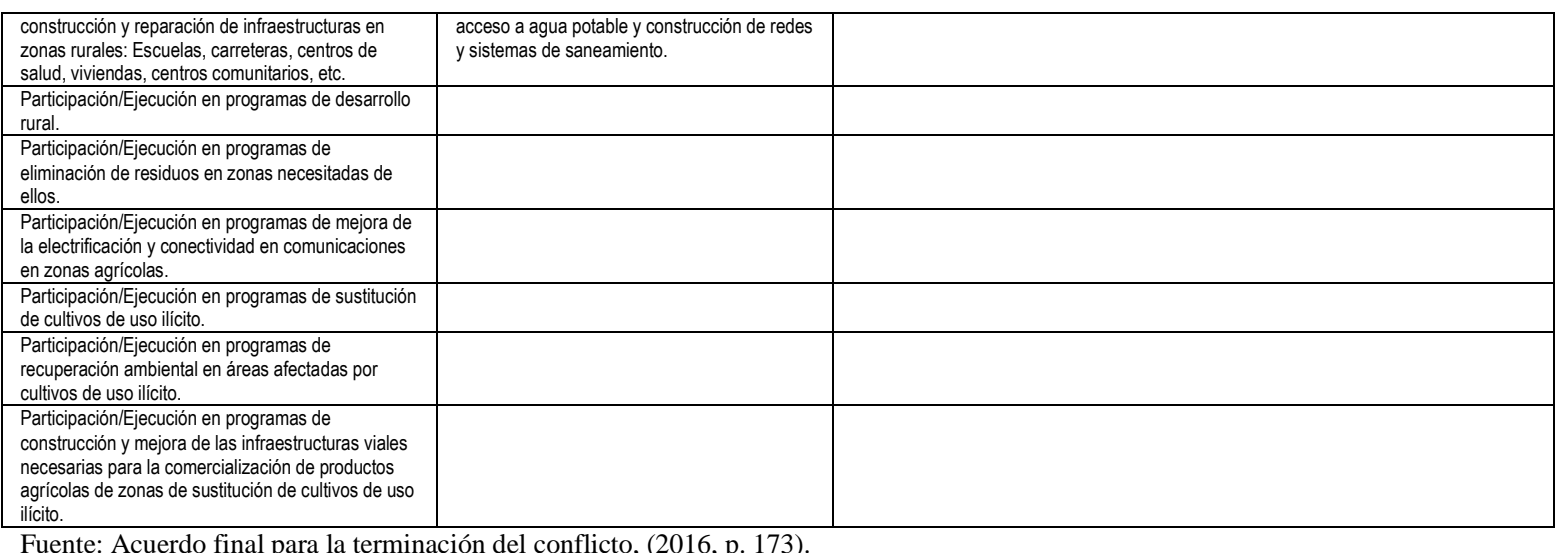

El segundo tipo de sanción, se aplica a los casos en los cuales se efectúe un tardío reconocimiento de la responsabilidad ante la comisión de graves delitos con ocasión del conflicto armado. Este tipo de circunstancia puede ser ejemplificado en aquellos individuos que pretendan guardar silencio o desconocer su responsabilidad en hechos victimizantes con el propósito de garantizarse la impunidad sobre ellos. Si así lo han querido, pero deciden tardíamente reconocer su culpa, la sanción a imponer será de entre 5 a 8 años de prisión esta vez en condiciones de reclusión ordinarias, es decir al interior de un establecimiento carcelario tradicional.

Finalmente, el tercer tipo de pena será establecido para aquellos individuos que se nieguen a reconocer su responsabilidad en la comisión de estos delitos relacionados con el conflicto armado y que habiendo agotado el debido procedimiento judicial estipulado para el esclarecimiento de su responsabilidad, sean hallados culpables, caso en el cual se les impondrá una pena de prisión en circunstancias ordinarias de entre 15 y 20 años. Es importante señalar que, si bien las distintas sanciones establecidas en ambos modelos de justicia son suficientes para establecer una profunda diferencia entre estos mecanismos de transición, se debe señalar una diferencia que va más allá de la simple sanción original.

Esto se relaciona con el establecimiento, en el caso de la Ley 975 de 2005, de un periodo de prueba con posterioridad al cumplimiento de la pena alternativa original, de tal manera que para la conservación de los beneficios de la misma, el condenado debe observar durante un periodo igual a la mitad de la pena alternativa impuesta, un comportamiento social acorde con su proceso de reinserción. Este hecho implica que debe abstenerse de cometer cualquier tipo de conducta delictiva, presentarse de manera periódica a las citas estipuladas ante el Tribunal Superior del Distrito Judicial que le corresponda, observar el deber de informar cualquier cambio de residencia durante éste periodo, de tal manera que al cumplir satisfactoriamente la pena alternativa impuesta y las condiciones estipuladas para la libertad condicionada posterior, se puedan declarar formalmente extinguidas las penas -ordinaria y accesoria- (Ministerio de Justicia, 2016). Por su parte, si bien en el modelo transicional aplicable a las FARC-EP el tercer tipo de sanción, es decir aquellas aplicables a quienes no

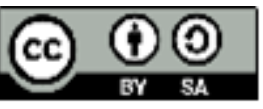


reconozcan verdad y responsabilidad, también tendrá un periodo de libertad a prueba, dicha prueba no se sujetara a un tiempo específico como en el modelo aplicado a las AUC.

Esto quiere decir que una vez cumplida la sanción impuesta en la sentencia, se le concederá la libertad al imputado. Esta libertad será puesta a prueba en el caso que el imputado se hubiese comprometido a promover actividades orientadas a la no repetición del daño causado una vez liberado y ello haya sido causa de disfrute de reducción de la duración de la pena impuesta. Sin embargo, el periodo de libertad a prueba se extinguirá dándose por cumplida la pena una vez acreditada la realización de la actividad de promoción de la no repetición del daño causado y en todo caso al cumplirse el tiempo de condena impuesta en la sentencia.

El tercer elemento diferenciador resaltado observa profundas diferencias existentes en materia de participación política. En este punto se debe indicar cómo en el modelo de justicia transicional desarrollado con los paramilitares, el tema de la participación política de los miembros de esta organización no fue plasmado como una eventual posibilidad. Dicha circunstancia queda expuesta si se considera como la narrativa paramilitar pretendía precisamente presentar en todo momento su accionar criminal como delitos políticos, postura que por supuesto es absolutamente alejada de la realidad (Schlenker \& Iturralde, 2006, p. 45). En este sentido, la Corte Suprema de Justicia ${ }^{7}$ se pronunció en el proceso contra Orlando César Caballero Montalvo, un paramilitar acusado por concierto para delinquir agravado y fabricación, tráfico y porte ilegal de armas de uso privativo de las fuerzas armadas, quien solicitó una cesación de procedimiento, pretendiendo ser procesado por delitos políticos y no por los mencionados. Dicha jurisprudencia fue un antecedente fundamental para negar cualquier status político al paramilitarismo y que sus acciones finalmente fueran cobijadas como delitos comunes, específicamente bajo la modalidad de concierto para delinquir agravado, dejando a quienes fueran condenados al margen de cualquier posibilidad de una eventual participación política (Paredes, 2007; Colectivo de Abogados, 2007).

En el acuerdo de justicia celebrado con las FARC-EP, si bien la participación política no ocupa un lugar central, este tema si obtiene una posición de importancia en la agenda de negociación que el gobierno y las FARC-EP han suscrito para finalizar el conflicto en Colombia. Esto en razón a que el proceso de dialogo tiene múltiples finalidades, sin embargo, no se puede afirmar que entre ellas esté lograr un cambio en el pensamiento o ideología de las FARC-EP, o que ésta organización renuncie a sus aspiraciones de llegar al poder político en el país. Precisamente por esto, lo que se pretende es conseguir que esta organización guerrillera pueda mantener su pensamiento, ideología o aspiración de poder, pero que renuncie a la violencia como mecanismo para la consecución de estos objetivos.

\footnotetext{
${ }^{7}$ Corte Suprema de Justicia de Colombia. Sentencia 117 de julio 11 de 2007.

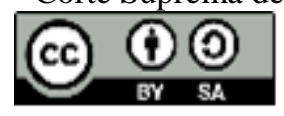


La participación política por ende, se constituye como un punto neurálgico en la transición hacia el posconflicto, y el acuerdo obtenido entre las partes en este punto precisamente reconoce la naturaleza política que engendró el movimiento subversivo décadas atrás, reconoce a las FARC-EP como un interlocutor político, proporciona garantías para su papel como eventual contrincante en el juego democrático y fundamentalmente establece que la imposición de cualquier sanción al interior del SIVJRNR no inhabilitara para la participación política ni limitara el ejercicio de ningún derecho, activo o pasivo de participación política.

Es tal la trascendencia de este punto en la negociación del fin de las hostilidades, que se ha acordado el establecimiento de una circunscripción electoral especial para el Congreso en aras de garantizar una adecuada participación política a favor de la población en las zonas afectadas por el conflicto durante las últimas décadas (Villarraga, 2015). De igual manera, es importante resaltar los compromisos que en materia de garantías para el desarrollo de la oposición política ha adquirido el Estado, así como los compromisos que el acuerdo ha establecido para la protección física de estas manifestaciones políticas de oposición, de tal manera que se combata el paramilitarismo y no se evidencien procesos sistemáticos de aniquilamiento político similares a los acontecidos con la Unión Patriótica y otros sectores de izquierda en la década de los ochenta, precisamente como consecuencia de unos avances en negociaciones entre el Gobierno nacional de entonces y las FARC-EP ${ }^{8}$.

Seguidamente, en cuanto a la diferencia existente respecto al esclarecimiento de los hechos en torno al conflicto y la construcción de una memoria histórica, se puede afirmar que este punto en el acuerdo suscrito con los paramilitares, quedó relegado a las confesiones realizadas por los miembros de las AUC en las llamadas versiones libres descritas en el artículo 17 de la Ley 975 de 2005. Por lo tanto, el esclarecimiento de muchos hechos ha quedado limitado a instrumentos de carácter judicial que pueden conllevar a la atribución de responsabilidades criminales, aspecto que en muchos casos propicia el silencio en torno a revelaciones circunstanciales de hechos victimizantes, más que a la divulgación y esclarecimiento de los mismos.

\footnotetext{
${ }^{8}$ La Unión Patriótica surgió como una tercera fuerza política de gran importancia para la vida democrática del país en la década del 80, como consecuencia de los diálogos de paz entre el Gobierno de Belisario Betancur y las FARC-EP. Representó un esfuerzo electoral que como movimiento político desde la legalidad aglomeró diversas fuentes de izquierda y sectores de oposición política. Sin embargo entre 1985 y 1988 se cometieron más de 650 asesinatos en contra de este movimiento político, al punto que tan solo a finales de 1986, el primer año electoral de la Unión Patriótica, ya habían sido asesinados 3 de sus más importantes dirigentes elegidos al Congreso de la República. Adicionalmente también fueron asesinados 1 diputado y 11 concejales en él Meta, 1 magistrado en Santander, 61 dirigentes y activistas de Juntas Patrióticas, 69 militantes de base, 24 guerrilleros en tregua y 34 simpatizantes (Campos, 2008, p. 24).
}

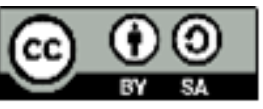


El esclarecimiento de los hechos y la construcción de una verdad histórica, sin embargo, han obtenido un sitial de importancia en el acuerdo de justicia y víctimas celebrado entre el Gobierno y las FARC-EP, al punto de haberse establecido finalmente la creación de la CEVCNR como elemento fundamental y necesario en el proceso de construcción de paz en el país. Esta circunstancia es absolutamente relevante, pues tal como se describe en la siguiente Tabla, son varios los informes de investigación de origen estatal o provenientes de la sociedad civil que se han dado en Colombia en torno a la necesidad de presentar un recuento histórico respecto a las causas, naturaleza y dinámica de la violencia social y política experimentada en el país a lo largo de varias décadas, sin que hasta el momento se hubiese desarrollado formalmente una Comisión de la Verdad como tal.

Tabla 3. Experiencias de Construcción de Memoria Histórica.

\begin{tabular}{|c|c|c|c|c|c|c|c|c|c|}
\hline 1957 & 1962 & 1987 & 1991 & 1995 & 1999 & 2001 & 2008 & 2013 & $2006-2013$ \\
\hline 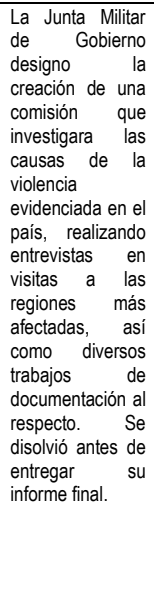 & 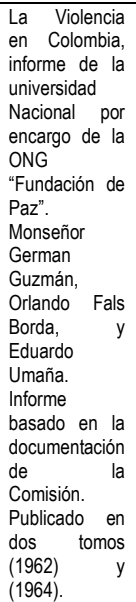 & $\begin{array}{l}\text { Comisión de } \\
\text { estudios sobre } \\
\text { la violencia. } \\
\text { Colombia: } \\
\text { Violencia y } \\
\text { Democracia. } \\
\text { Gonzalo } \\
\text { Sánchez et al, } \\
\text { Instituto de } \\
\text { Estudios } \\
\text { Políticos y Rel. } \\
\text { Internacionales } \\
\text { (IEPRI). } \\
\text { Universidad } \\
\text { Nacional, por } \\
\text { encargo del } \\
\text { Gobierno } \\
\text { nacional. }\end{array}$ & $\begin{array}{l}\text { Informe } \\
\text { pacificando la } \\
\text { paz. } \\
\text { Resultado del } \\
\text { acuerdo entre } \\
\text { el Gobierno } \\
\text { nacional y el } \\
\text { EPL. Grupo } \\
\text { de } \\
\text { investigación } \\
\text { encabezado } \\
\text { por Alejandro } \\
\text { Reyes. }\end{array}$ & $\begin{array}{l}\text { Colombia: } \\
\text { Nunca Más! } \\
\text { Comisión } \\
\text { Intereclesial } \\
\text { de Justicia y } \\
\text { Paz. }\end{array}$ & $\begin{array}{l}\text { Informe sobre } \\
\text { desplazamiento } \\
\text { y violencia } \\
\text { CODHES. }\end{array}$ & $\begin{array}{l}\text { I Informe } \\
\text { sobre } \\
\text { violencia } \\
\text { sociopolítica } \\
\text { contra } \\
\text { mujeres y } \\
\text { niñas en } \\
\text { Colombia. } \\
\text { Comisión } \\
\text { Colombiana } \\
\text { de Juristas. }\end{array}$ & $\begin{array}{l}\text { Comisión de } \\
\text { la Verdad } \\
\text { sobre los } \\
\text { hechos del } \\
\text { Palacio de } \\
\text { Justicia de } 6 \\
\text { y } 7 \text { de } \\
\text { noviembre de } \\
1985 \text {. } \\
\text { Designada } \\
\text { por las cortes. }\end{array}$ & $\begin{array}{l}\text { Basta Ya! } \\
\text { Colombia: } \\
\text { Memorias de } \\
\text { Guerra y } \\
\text { Dignidad, } \\
\text { Grupo de } \\
\text { Memoria } \\
\text { Histórica } \\
\text { nombrado por } \\
\text { la Comisión } \\
\text { Nacional de } \\
\text { Reparación y } \\
\text { Reconciliación } \\
\text { en 2006, con } \\
\text { base en el } \\
\text { mandato de la } \\
\text { ley 495 de } \\
2005 \text {. }\end{array}$ & $\begin{array}{l}\text { Numerosos } \\
\text { estudios de } \\
\text { casos: Trujillo, } \\
\text { Catatumbo, } \\
\text { Magdalena } \\
\text { Medio y } 20 \\
\text { más del } \\
\text { Grupo de } \\
\text { Memoria } \\
\text { Histórica, del } \\
\text { Centro } \\
\text { Nacional de } \\
\text { Memoria } \\
\text { Histórica. }\end{array}$ \\
\hline
\end{tabular}

Fuente: González (2013).

Por ende, la importancia respecto a la creación de la CEVCNR se asocia a los beneficios derivados de estas instituciones de transición a través de un proceso terapéutico de catarsis producto del reconocimiento del pasado, de averiguar los hechos, de relatarlos y difundirlos y así contribuir a la creación de una memoria compartida. Esto solo es posible cuando las sociedades optan por encarar la tragedia asociada al escenario de violencia generalizada que se pretende superar, antes que preferir optar por el olvido y la negación del mismo. Respecto a la inconveniencia del olvido y a la defensa a la memoria, se pronuncian Fuentes y Cote (2004, p. 12), señalan:

(...) Se suele apelar, en favor del olvido a razones pragmáticas, cuando las éticas se revelan inconscientes. Se dice que si no se olvida el pasado violento, la memoria de este podría desencadenar nuevamente odios y retaliaciones que reeditarían la violencia. El trasfondo de este argumento, es una lectura psicológica, equivale a la convicción de que las heridas del alma pueden ser sanadas simplemente ignorándolas y tapándolas; en una lectura sociológica, equivale a la convicción de que una sociedad puede construir un futuro no violento o de sana convivencia, sobre la

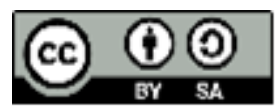


ignorancia compulsiva de su historia; en una lectura moral, equivale a la convicción de que sobre la abdicación de la conciencia moral frente al pasado, puede construirse una responsabilidad moral frente al presente y al futuro. Ninguna de estas lecturas es aceptable.

El quinto elemento diferenciador se evidencia en el otorgamiento de indultos y amnistías, ante lo cual es importante señalar cómo en el acuerdo desarrollado con las AUC, no se estipularon dichos mecanismos, pues básicamente lo implementado con esta organización fue un acuerdo de sometimiento a la justicia donde si bien no aplicaban estas figuras, ante el cumplimiento de unas condiciones de colaboración, se estableció la posibilidad de acceder a una suspensión de la pena o a la imposición reducida de una. En el caso de las FARC-EP, la posibilidad de acceder a estas figuras de gracia en materia de responsabilidad para delitos políticos y conexos, quedó efectivamente plasmada en el acuerdo final, excluyendo el acceso a estas figuras para aquellos individuos criminalmente responsables por delitos descritos en los numerales 40 y 41 del acuerdo definitivo entre las partes 9 .

El hecho de que estas medidas de amnistías e indultos no se apliquen para aquellos individuos con responsabilidad criminal frente a crímenes internacionales, garantiza el balance mínimo requerido para nivelar las obligaciones del Estado en materia de investigación y juzgamientos de estos delitos y las concesiones otorgadas por el Gobierno nacional en torno a la construcción de paz en el país en medio del proceso de dialogo con las FARC-EP. Los diversos sectores que rechazan de plano la posibilidad de emplear estos instrumentos de gracia, subestiman realidades normativas reconocidas ampliamente por el Derecho Penal Internacional, especialmente a las concesiones permitidas en el artículo 6(5) del Protocolo II adicional a las Convenciones de Ginebra.

La siguiente diferencia, respecto a las autoridades judiciales involucradas en ambos mecanismos de justicia transicional, revela dos realidades. Por un lado en el proceso de justicia implementado con las AUC, la jurisdicción y competencia para la investigación y juzgamiento de los delitos cometidos por miembros de esta organización ha estado enteramente centrada en las autoridades judiciales de orden nacional. Han sido precisamente éstas quienes, para bien o para mal, han soportado el peso del permanente escrutinio nacional e internacional frente a los ambivalentes resultados que hasta la fecha arroja la implementación de la Ley 975 de 2005. En el acuerdo de justicia con las FARCEP, si bien la JEP también aplicará procedimientos acordes con la Constitución y las leyes

\footnotetext{
${ }^{9}$ Estos numerales establecen que no procederá la amnistía ni el indulto para delitos de lesa humanidad, genocidio, graves infracciones al derecho internacional humanitario cometidas de forma sistemática o como parte de un plan o política, la toma de rehenes u otra privación grave de la libertad, la tortura, las ejecuciones extrajudiciales, la desaparición forzada, el acceso carnal violento y otras formas de violencia sexual, la sustracción de menores, el desplazamiento forzado, además del reclutamiento de menores, todo ello conforme a lo establecido en el Estatuto de Roma, así como para aquellos delitos comunes que carecen de relación con la rebelión.
}

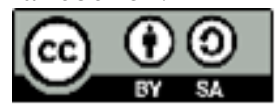


nacionales, se ha establecido que para la sanción de criminales por violaciones graves a los derechos humanos e infracciones igualmente relevantes al Derecho internacional humanitario, el Tribunal de Paz - integrado por colombianos - podrá también contar con la participación de juristas extranjeros a modo de amicus curiae ${ }^{10}$, que ingresaran a una sección del Tribunal cuando sea solicitado por el propio acusado en un caso específico. Esta figura puede ser entendida, como los amigos de la corte o bien en su acepción más actual del tribunal, y esta puede ser definida, como aquellas presentaciones, que pueden realizar terceros ajenos a una disputa judicial, siempre y cuando posean un interés justificado en la resolución final del litigio, esto con el propósito de expresar sus opiniones en torno a la materia en cuestión, dar aportes de trascendencia para la sustentación del proceso judicial (López, 2011, p. 9).

Ante esta particularidad, la presencia de personal extranjero en este modelo de justicia, se puede considerar como un impulso positivo, pues su aporte se puede traducir en mayores garantías para la observancia de estándares procedimentales de índole internacional, el involucramiento de expertos internacionales en la materia y en general una contribución en experiencia, recursos y conocimientos técnicos, en aras de otorgar mayor legitimidad a éste modelo de justicia (Costi, 2005).

Con relación a las diferencias existentes entre ambos modelos de justicia transicional en lo referido a la participación de las víctimas, es importante resaltar el notable aporte dado por ellas en la estructuración del acuerdo de justicia y víctimas celebrado entre el Gobierno y las FARC-EP. En este sentido, resulta adecuado agregar como alrededor de 60 víctimas de hechos cometidos por diversos actores del conflicto armado, previamente seleccionadas observando criterios de equilibrio de género y pluralismo, viajaron a La Habana representando negritudes, indígenas, mujeres, afrodescendientes, comunidad LGTBI, empresarios, sindicalistas y campesinos entre otros, con el propósito de presentar propuestas y hacer escuchar sus reclamos como víctimas directamente ante los negociadores tanto del Gobierno como de las FARC-EP. Adicionalmente, miles de víctimas contribuyeron a la construcción de este acuerdo mediante su participación en el desarrollo de diversos foros nacionales y regionales de víctimas, en los cuales tomaron parte más de 3.500 personas, y que fueron desarrollados con el propósito de proporcionarles un espacio de dignificación y reconocimiento, así como de recepción sistematizada de sus propuestas e iniciativas como forma inicial de un proceso de reconciliación (PNUD, 2014).

\footnotetext{
${ }^{10}$ Para mayor información Véase Pascual, F. (2011). El desarrollo de la institución del amicus curiae en la jurisprudencia internacional. Revista Electrónica De Estudios Internacionales., 21, 1-37; Losardo, M. (2014). Amicus curiae en el plano internacional. Lecciones y Ensayos, 92, 101-128; Kochevar, S. (2013). Amici Curiae in Civil Law Jurisdictions. The Yale Law Journal, 122(6), 1653-1669.
}

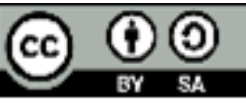


Esta circunstancia sin duda le imprime una connotación diferenciadora a este reciente modelo de justicia, que no tuvo la experiencia transicional de las AUC. En este sentido, se debe señalar cómo el modelo de justicia concertado con esta organización paramilitar adoleció de este tipo de acompañamiento y participación por parte de las víctimas del conflicto armado, tanto en su etapa de diseño como en su proceso de implementación. El papel de las víctimas en el marco de la Ley 975 de 2005 ha quedado rezagado principalmente a su participación en las audiencias judiciales de juzgamiento y reparación. Las reclamaciones de las organizaciones de víctimas y de derechos humanos por los derechos a la verdad, justicia y reparación, no contaron con la visibilidad y el respaldo político que parecían tener las propuestas de seguridad y orden lideradas por el gobierno de Álvaro Uribe (Gómez, 2012).

Otro aspecto relacionado a las diferencias entre estos modelos de justicia tiene que ver con la posibilidad de desarrollar un proceso discrecional de selectividad para investigar y juzgar responsabilidades criminales. Esta particularidad se desprende de la experiencia vivida durante la implementación de la Ley 975 de 2005, específicamente respecto a cómo la ausencia inicial de esta potestad selectiva repercutió en el notorio desborde de las capacidades operativas de las instituciones judiciales colombianas, frente a los miles de actos de criminalidad derivados del aterrador accionar paramilitar. Es una realidad evidente que el número de acciones criminales derivadas del paramilitarismo, simplemente rebosó cualquier posibilidad real de realizar una adecuada labor de investigación y juzgamiento sobre la responsabilidad de los imputados sobre cada una de ellas. La siguiente tabla da muestra de tan solo algunas de las más emblemáticas acciones de violencia paramilitar.

En este sentido, el acuerdo de justicia entre el Gobierno y las FARC-EP se articula de forma vinculante con las disposiciones emanadas del Acto Legislativo 01 de 2012 y la autorización de carácter constitucional que desarrolla este instrumento normativo para la implementación en mecanismos transicionales, de criterios de selección y priorización de la acción penal del Estado ${ }^{11}$. Por muy controversial que pueda resultar esta circunstancia, ella se fundamenta en una realidad absolutamente irrefutable, respecto a cómo es absolutamente imposible para un Estado como Colombia judicializar todas y cada una de las conductas delictivas que se hayan ocasionado a lo largo de los últimos cincuenta años de confrontación armada al interior del país.

\footnotetext{
${ }^{11}$ La directiva 001 de 2012 de la Fiscalía General de la Nación, define como criterio de priorización a aquellos parámetros lógicos que sirven para focalizar la acción investigativa de la Fiscalía General de la Nación hacia determinadas situaciones y casos, con el fin de asegurar un mayor impacto y un mejor aprovechamiento de los recursos administrativos y logísticos. Entre estos criterios se encuentran - aunque no se limitan - la gravedad del crimen al interior del conflicto, los máximos responsables de su comisión, la representatividad del caso, entre otros.
}

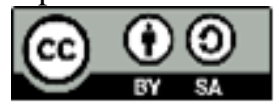


La siguiente diferencia marcada entre los modelos transicionales celebrados con las AUC y las FARC-EP respectivamente gira en torno al proceso de desarme de ambas estructuras. En el primer caso, el proceso de desarme de las AUC fue paulatino, desigual e incompleto, y la entrega de sus armas se fue realizando de manera postergada en la medida en que se iban desarticulando los diferentes frentes y bloques de guerra de esta organización alrededor del país, tomando cerca de 4 años para completarse un desarme que significó la entrega de cerca de 18.000 armas de fuego (Escuela de Cultura de Paz, 2008, p. 122). Adicionalmente, muchas de sus estructuras armadas no se acogieron al proceso de negociación con el Estado, marginándose de cualquier posibilidad real de abandonar las armas y cesar su papel victimizante al interior del conflicto, mientras que otras estructuras, después de haber entregado tan solo parte de su arsenal, optaron por el rearme.

Respecto al proceso de desarme de las FARC-EP, esta guerrilla ha sido enfática en su insistencia en no hablar de entrega de armas, pues, sostienen que ello implicaría el reconocimiento de una derrota frente a un adversario militarmente muy superior, cosa que no ocurrió. En este sentido, entre las FARC-EP y el Gobierno nacional se ha establecido un cronograma de 180 días para el cese y dejación de armas, contados a partir de la firma del acuerdo final, tal como se ilustra en la siguiente figura.

Figura No. 1. Cronograma respecto a la dejación de armas.

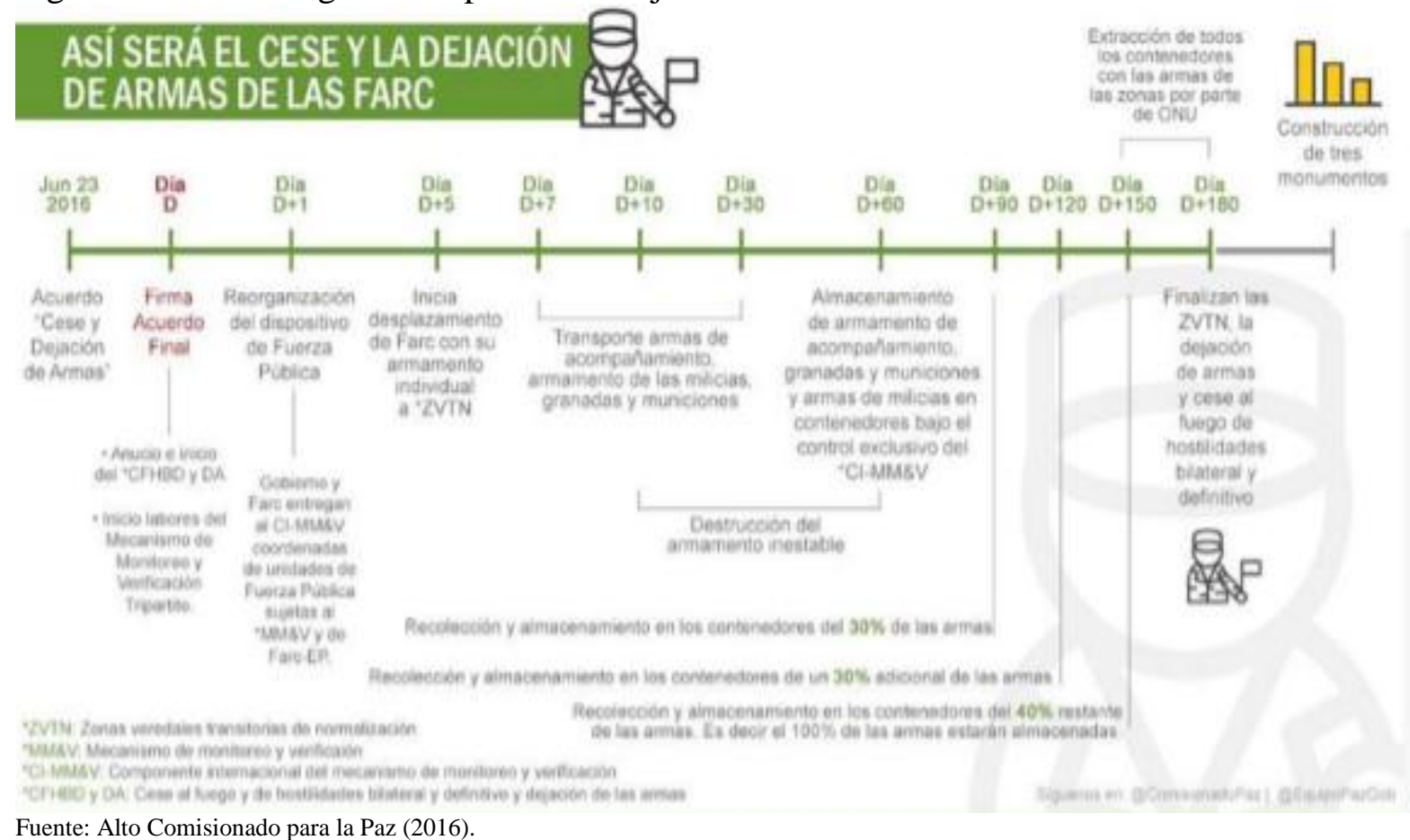

Fuente: Alto Comisionado para la Paz (2016).

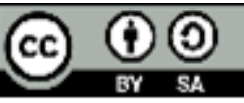


Frente a este tema, vale la pena resaltar que si bien el proceso de paz implementado con las AUC ha contado con el apoyo de la comunidad internacional, es especialmente el acompañamiento desde el 2004 de la Organización de Estados Americanos (OEA) a través de su Misión de Apoyo al proceso de Paz en Colombia (MAPP/OEA) ${ }^{12}$, una de sus características más notorias. Mientras, el proceso de desarme de las FARC-EP contará con una misión de acompañamiento internacional de la Organización de las Naciones Unidas (ONU), apoyada con vehemencia por su Consejo de Seguridad ${ }^{13}$ en la cual expresamente señala:

(...)Decide también que la Misión será una misión política, integrada por observadores internacionales desarmados, que se encargará de vigilar y verificar la dejación de las armas y formará parte del mecanismo tripartito que vigilará y verificará el cese del fuego y de las hostilidades bilateral y definitivo, de conformidad con el Comunicado Conjunto, y que comenzará todas las actividades de vigilancia y verificación, con lo que empezará a contar el período de 12 meses, tras la firma del Acuerdo Final de Paz por el Gobierno de Colombia y las FARCEP.

La décima diferencia valorada se localiza en la aplicación de la figura de la extradición por parte del Estado colombiano. La aplicación de este mecanismo de cooperación judicial fue suspendida respecto a la cúpula paramilitar como consecuencia de la negociación en que se encontraban el Gobierno y las AUC, pues en aquel momento varios de los más emblemáticos líderes paramilitares que participaban en las negociaciones se encontraban pedidos en extradición por parte de los Estados Unidos ${ }^{14}$.

El proceso de negociación con el gobierno motivó que muchos narcotraficantes buscaran refugio seguro de la extradición, haciéndose pasar por comandantes paramilitares a través de la compra de franquicias y estructuras armadas al interior de las AUC, esperando recibir penas alternativas por su largo prontuario criminal en el marco del instrumento de justicia transicional acordado con el Gobierno. Este hecho adiciona una crítica razonable al proceso de transición desarrollado con los paramilitares, que tal como se ha establecido fue parcial, pues no todos los paramilitares se desmovilizaron, pero adicionalmente a eso, no todos los que se desmovilizaron eran paramilitares ${ }^{15}$.

\footnotetext{
${ }^{12}$ Concejo Permanente de la Organización de Estados Americanos. Resolución 859 (1397/04).

${ }^{13}$ Concejo de Seguridad de las Naciones unidas. Resolución 2261 de 2016.

${ }^{14}$ Algunos de los jefes paramilitares pedidos en extradición, eran Salvatore Mancuso, Rodrigo Tovar Pupo alias "Jorge 40", Diego Fernando Murillo alias "Don Berna", Iván Roberto Duque alias "Ernesto Báez", Ramiro Vanoy alias "Cuco Vanoy", Carlos Mario Jiménez alias "Macaco", Juan Carlos Sierra alias "El Tuso", Edwin Mauricio Gómez alias "El Mello"y Hernán Giraldo entre otros.
}

15 Algunos de los casos más emblemáticos en este sentido se encuentran en cabeza de grandes capos de la droga en Colombia. Entre quienes destacan figuras como Juan Carlos Sierra alias "El Tuso", quien habría (요 
La suspensión de la aplicación de esta figura solo se contemplaba para quienes finalizaran con sus actividades delictivas transnacionales en el marco de las negociaciones con el Estado y al cumplimiento de sus compromisos de aportar a la verdad, la justicia, la reparación y las garantías de no repetición. Esta circunstancia sirvió de fundamento para que finalmente el Gobierno del expresidente Uribe, alegando razones de incumplimiento por parte de líderes paramilitares, el 13 de mayo de 2008 autorizara la reactivación de esta figura de manera masiva al enviar a los Estados Unidos a 14 jefes paramilitares solicitados por este país por delitos de narcotráfico (Human Rights Watch, 2008, p. 72).

Ahora bien, en el caso de la aplicación de la extradición con las FARC-EP, la aplicación de este mecanismo fue igualmente suspendida como consecuencia de la negociación adelantada con el Gobierno nacional ${ }^{16}$. En este sentido, la principal diferencia entre ambos modelos de justicia gira entorno a la explícita garantía establecida en el acuerdo final entre las partes (p. 169, numeral 72) para suspender la aplicación de esta medida de forma extensiva, es decir, no solo salvaguardando a los cabecillas de esta organización, sino de forma amplia a todo individuo acusado de pertenecer a las FARC-EP, por la comisión de conductas realizadas con anterioridad a la firma del acuerdo final entre las partes.

El carácter extensivo de esta circunstancia no se limita a cobijar solo a miembros de las FARC-EP o personas acusadas de pertenecer a esta organización, pues de hecho esta particularidad implica una cobertura incluso a familiares de miembros de esta guerrilla. En este sentido el acuerdo de justicia y víctimas en su numeral 72 señala textualmente:

cuando exista una solicitud de extradición respecto de familiares hasta el segundo grado de consanguinidad o primero de afinidad, de integrantes de las FARC-EP o de una persona acusada o señalada en una solicitud de extradición de ser integrante de dicha organización, este supuesto podrá ser sometido a la Sección de Revisión del Tribunal para la Paz para que decida si la solicitud obedece a hechos o conductas relacionados con la pertenencia, o acusación de pertenencia, a

pagado cerca de 2 millones de dólares por dicha franquicia y eventualmente se desmovilizaría como Comandante del Bloque Héroes de Granada (2005), los hermanos Miguel Ángel Mejía Múnera y Víctor Manuel Mejía Múnera, alias "Los Mellizos", habrían pagado cerca de 2 millones de dólares, por la franquicia del Bloque Héroes de Arauca, Francisco Javier Zuluaga alias "Gordolindo" quien habría pagado 2 millones de dólares por la franquicia del Bloque Pacifico, José Miguel Arroyave alias "Arcángel", quien habría pagado entre 5 y 7 millones de dólares por la franquicia del Bloque Centauros y quien sería un importante gestor del Bloque Capital, entre otros (Semana, 2004; El Tiempo, 2007).

${ }^{16}$ En el caso de las FARC-EP varios de sus máximos dirigentes han sido igualmente solicitados en extradición. Entre estos se destacan figuras como Rodrigo Londoño Echeverry alias "Timochenko", Jorge Torres Victoria alias "Pablo Catatumbo", Luciano Marín Arango alias "Iván Márquez", Félix Antonio Muñoz alias "Pastor Alape", Adán de Jesús Jiménez García alias "Conejo" y Omar de Jesús Restrepo Correa alias "Olmedo", entre otros.

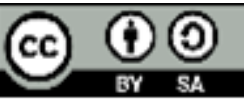


las FARC-EP del familiar del solicitado en extradición. De obedecer a esta causa, por tratarse de un señalamiento o acusación por conductas que nunca antes han sido objeto de solicitudes de extradición ni reúnen las condiciones para ello, la Sección podrá denegar la extradición y en ese caso decidir si el hecho o la conducta es competencia del SIVJRNR o si debe ser investigada o juzgada por la jurisdicción penal ordinaria.

Esta concesión en materia de justicia representa un importante incentivo para aquellos que decidan acogerse al SIVJRNR y evitar comparecer ante autoridades extranjeras, como las norteamericanas por ejemplo, con criterios punitivos muchos más severos de los que eventualmente tendrán que asumir en medio de este proceso de transición. Esta circunstancia ha sido plenamente apoyada por los Estados Unidos, pese a que la extradición ha sido un importante instrumento de cooperación judicial entre las autoridades de ambos países, un eje central en su alianza estratégica, al punto que tan solo entre el 2002 y el 2015 desde Colombia se enviaron más de 2.000 individuos extraditados hacia Norteamérica (Whitaker, 2015).

Finalmente, la diferencia restante entre estos dos modelos puede evidenciarse en el hecho que el modelo de justicia transicional negociado y acordado con las AUC no fue sometido a ningún tipo de refrendación por parte del pueblo colombiano, mientras que en el caso del desarrollado con las FARC-EP fue sometido a votación popular a través de la figura de plebiscito $^{17}$, siendo rechazado en su forma inicial en la votación a la que fue sometida en el mes de octubre de $2016^{18}$.

La refrendación del acuerdo final y definitivo para la terminación del conflicto en Colombia siempre fue presentada desde el establecimiento político nacional, como una manera genuina y transparente de consultar a la sociedad colombiana respecto al contenido del mismo. Ante la derrota en las urnas el pasado mes de octubre, los equipos negociadores de ambas partes iniciaron unos trabajos de renegociación sobre aspectos emblemáticos que habían servido a sectores de oposición para criticar el acuerdo inicial. De momento no está

\footnotetext{
${ }^{17}$ El artículo 103 de la Constitución Política de Colombia establece que el plebiscito es un mecanismo de participación popular en virtud de su soberanía. Es decir, con este instrumento el Gobierno somete a consideración popular alguna determinación del ejecutivo, en aras de que sea el pueblo soberano quien la aprueba o rechaza.

${ }^{18}$ El Gobierno nacional a través de la Ley 156 de 2015, estableció la regulación del plebiscito para la refrendación del acuerdo final para la búsqueda de la terminación del conflicto armado en Colombia y la construcción de una paz estable y duradera, y en el cual se estableció un umbral requerido del 13\% del total del censo electoral para la aprobación de este acuerdo, es decir, este mecanismos de refrendación requerirá cerca de 4.4 millones de votos a favor (Rojas, 2016; lafm, 2016). Ante la pregunta ¿Apoya usted el acuerdo final para terminar el conflicto y construir una paz estable y duradera? Se obtuvo una votación final de 6.431 .376 votos por el NO (50.2\%) y 6.377 .482 votos por el SÍ $(49.7 \%)$, es decir una victoria con una pequeña ventaja de alrededor de 50 mil votos (El Espectador, 2016; El País, 2016).
}

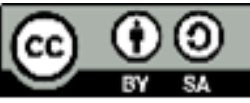


clara la figura mediante la cual se opte por obtener la refrendación de este acuerdo final, pero lo cierto es que en el texto del acuerdo final (2016, p. 219) se mantienen abierta las posibilidades de que sea hecho mediante mecanismos de participación ciudadana como lo son el plebiscito, la consulta popular, el cabildo abierto, la iniciativa legislativa o por corporaciones públicas elegidas mediante sufragio sobre cuyos miembros recaiga representación con mandato tales como el Congreso de la Republica, las Asambleas Departamentales y Concejos Municipales. Dado los resultados adversos obtenidos en el pasado plebiscito es muy probable que esta figura se descarte y lo más natural es que se opte por obtener su refrendación a través de otros mecanismos.

\section{Conclusiones}

Los contenidos del acuerdo de justicia y víctimas acordado entre el Gobierno nacional y las FARC-EP, representan un modelo de justicia transicional absolutamente diferente al implementado con las AUC. Si bien en esencia se tratan de instrumentos que fueron desarrollados en el mismo contexto de violencia generalizada, responden a contenidos, desarrollos y aspiraciones profundamente diferentes.

Adicionalmente, el modelo transicional acordado con las FARC-EP se constituye como un importante referente en la disciplina de la justicia transicional a nivel internacional, dado lo novedoso y práctico de sus estipulaciones. En este sentido, su contenido evidencia un proceso de transformación y adaptación a las realidades políticas y sociales propias del país, enriqueciéndose de las lecciones y errores pasados, para así brindar mecanismos de transición cada vez más consolidados. Esta circunstancia ha insertado a Colombia en el centro de la discusión y análisis de la justicia transicional a nivel internacional y si bien es muy pronto para determinar si esta experiencia podrá superar los múltiples retos y desafíos que conlleva su implementación, o establecer que efectivamente este modelo podrá garantizar una efectiva transición hacia el post-conflicto y la normalización democrática en el país dado que se trata de un tema en pleno desarrollo, es oportuno señalar que los implacables señalamientos de impunidad y falta de garantías para garantizar los derechos a la verdad, la justicia, la reparación y la no repetición contra el modelo transicional aplicable a las FARC-EP, son en el mejor de los caso, exagerados.

Mientras que el modelo aplicado a las AUC tuvo más implicaciones de ser un sometimiento a la justicia, parcial, desarrollado de espalda al país, sin participación de las víctimas, sin mecanismos de refrendación, que desbordó las capacidades de las autoridades judiciales de carácter nacional, el modelo transicional diseñado entre el Gobierno y las FARC-EP, goza de los elementos necesarios para poder establecerse como la experiencia transicional más desarrollada y completa en la historia actual del país.

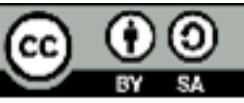




\section{Referencias}

Acuerdo final para la terminación del conflicto y la construcción de una paz estable y duradera, (2016). Recuperado desde https://www.mesadeconversaciones.com.co/sites/default/files/12-1479102292.11$\underline{1479102292.2016 \text { nuevoacuerdofinal-1479102292.pdf }}$

Alto Comisionado para la Paz, (2016). Acuerdo sobre Cese al Fuego y de Hostilidades Bilateral y Definitivo y Dejación de Armas, Garantías de Seguridad y Refrendación.

Ambos, K. (2009). El marco jurídico de la justicia de transición. In Justicia de transición: Informes de América Latina, Alemania, Italia y España. Konrad Adenauer Stiftung

Campos, Y. (2008). El baile rojo: Relatos no contados del genocidio de la UP. Bogotá, D.C., Colombia: Icono.

Centro Nacional de Memoria Histórica, (2013). ¡Basta ya!: Colombia: Memorias de guerra y dignidad. Bogotá. Imprenta Nacional.

Colectivo de Abogados. (2007). Paramilitarismo o Sedición? Semanario Caja De Herramientas, 0079.

Concejo de Seguridad de las Naciones Unidas. Resolución 2261 de 2016.

Concejo Permanente de la Organización de Estados Americanos. Resolución $859(1397 / 04)$.

Corte Suprema de Justicia de Colombia. Sentencia 117 de julio 11 de 2007.

Costi, A. (2005). Hybrid Tribunals as a Valid Alternative to International Tribunals for the Prosecution of International Crimes. Human Rights Research, 3, 1-27.

El Colombiano, (2015). Las diferencias entre el proceso de paz de las Farc y las AUC.

El Espectador, (2016). Esta es la pregunta que se hara a los colombianos en el plebiscito por la paz.

El País, (2016). "Resistencia civil se sustentará con firmas", explicó senador Uribe. Recuperado desde http://www.elpais.com.co/elpais/colombia/procesopaz/noticias/resistencia-civil-sustentara-con-firmas-explico-senador-uribe

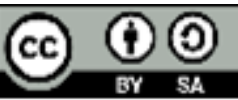


El Tiempo, (2007). Para convertirse en paramilitar, Juan Carlos Sierra, alias 'El Tuso', pagó $\$ 3.000$ millones.

El Universal. (2015). Similitudes y diferencias en los procesos de paz con las Farc y las Autodefensas.

Elster, J. (2004). Closing the Books: Transitional Justice in Historical Perspective.

Escuela de Cultura de Paz, (2008). Alerta 2008. Informe sobre conflictos, derechos humanos y construcción de paz. Barcelona. Icaria Editorial

Fuentes, D., \& Cote, G. (2004). El papel de las comisiones de la verdad en la formación de la memoria histórica: Construcción de un relato?

Gómez, G. (2012). Asimetrías del poder, resistencias y derechos de las víctimas frente a los procesos de justicia y paz. Revista Estudios De Derecho, 69(153), 89-112.

González, C. (2013). Los nombres de la guerra en la memoria histórica. Bogotá: Universidad nacional de Colombia.

Hayner, P. (2002). Unspeakable truths: Transitional justice and the challenge of truth commissions. Nueva York: Routledge.

Human rights Watch, (2008). ¿Rompiendo el control? Obstáculos a la justicia en las investigaciones de la mafia paramilitar en Colombia.

Kochevar, S. (2013). Amici Curiae in Civil Law Jurisdictions. The Yale Law Journal, 122(6), 1653-1669.

Lafm, (2016). ¿Quieren las Farc una consulta popular para refrendar los acuerdos?

López, A. (2011). El amicus curiae como protector de derechos humanos en México: Una aproximación al ideal del Estado de Derecho. Revista De Investigación En Ciencias Sociales Y Humanidades., 13, 1-31.

Losardo, M. (2014). Amicus curiae en el plano internacional. Lecciones y Ensayos, 92, 101-128.

Mani, R. (2002). Beyond retribution: Seeking justice in the shadows of war. Malden: Blackwaell.

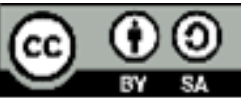


Minow, M. (1998). Between vengeance and forgiveness facing history after genocide and mass violence. Boston: Beacon Press.

Ministerio de Justicia, (2016). Ley de Justicia y Paz: Respuestas a sus preguntas. Recuperado desde http://www.justiciatransicional.gov.co/ABC/Ley-de-Justicia-y-Paz

Paredes, C. (2007). ¿Sí es posible concederles estatus político a los paramilitares? Bogotá: Semana.

Pascual, F. (2011). El desarrollo de la institución del amicus curiae en la jurisprudencia internacional. Revista Electrónica De Estudios Internacionales., 21, 1-37.

PNUD, (2014). Programa de las Naciones Unidas para el Desarrollo. Todo sobre los Foros Regionales y el Foro Nacional sobre Víctimas.

Pulzo, (2015). Diferencias y semejanzas entre la justicia para las Farc y la de grupos paramilitares.

Rojas, D. (2006). La internacionalización de la guerra: Estados Unidos y la guerra en Colombia. En Nuestra guerra sin nombre: Transformaciones del conflicto en Colombia. Bogotá: Instituto de Estudios Políticos y Relaciones Internacionales.

Schlenker, J., \& Iturralde, M. (2006). El uso del discurso de los derechos humanos por parte de los actores armados en Colombia: ¿Humanización del conflicto o estrategia de guerra? Revista Análisis Político, 56, 29-50.

Semana, (2004). ¿Cómo fue realmente asesinado Miguel Arroyave?: Crónica de una conspiración fríamente calculada.

Van Zyl, P. (2008). Promoviendo la Justicia transicional en sociedades post-conflicto. In Verdad, memoria y reconstrucción Estudios de caso y análisis comparado. Bogotá: International Center for Transitional Justice.

Villarraga, A. (2015). Los procesos de paz en Colombia, 1982-2014 (Documento resumen). Bogotá: Fundación Cultura Democrática.

Whitaker, K. (2015). EE.UU. respetará decisión de Colombia sobre no extradición de guerrilleros. Recuperado desde http://caracol.com.co/programa/2015/10/13/6am_hoy_por_hoy/1444741213_978037.html

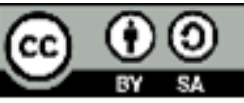

